\title{
Hugo Santiago (1939-2018)
}

\section{David Oubiña}

Hugo Santiago me contó que, un día, Aníbal Troilo no aparecía por ningún lado. Lo buscaron por todo Buenos Aires y nada. Siempre se escapaba cuando empezaba a caer la noche y, entonces, había que salir de pesquisa. O de pronto llamaba él, a la madrugada, para que pasaran a recogerlo por algún bar: "Lo espero en la puerta, pibe". Y dice Hugo que, cuando llegaban, Troilo estaba en la vereda dando saltitos para mostrar que, a pesar de los diez babys que se había tomado, estaba sobrio. Se acercaba al auto, se daba palmadas en la panza y se abotonaba el traje blanco: "Mire, pibe, mire: no me tiembla la mano". Así era siempre. Pero esta vez, parecía que se había esfumado. Cinco personas buscándolo, pensando dónde se había metido o si le había pasado algo. Fueron al bar de Paraguay y Paraná, preguntaron a los amigos, averiguaron en Caño 14. Nada. Hasta que a alguien se le ocurrió. Entonces, Hugo fue hasta la cancha de River y ahí estaba. Era domingo a la mañana y el partido empezaba varias horas más tarde. Pero ahí estaba Troilo, en la tribuna, roncando solo en medio del estadio desierto.

Eso era 1966. Santiago preparaba el que debería haber sido su primer largometraje, $E l$ hombre del bandoneón, a partir de un guión que había escrito con Olga Orozco y que iba a ser protagonizado por Troilo. El golpe de Onganía impidió el comienzo del rodaje y Hugo regresó a Europa donde había estado viviendo los años anteriores. El hombre del bandoneón nunca se realizó; pero veinte años más tarde, el bandoneonista (la idea del bandoneonista) reencarna en el personaje principal de Las veredas de Saturno (1985).

Las veredas de Saturno (escrita con Juan José Saer) es la secuela de Invasión, esa película que permanece como uno de los pocos tesoros del cine argentino. Invasión (1969) fue el acta fundacional de Aquilea, la ciudad mítica que es y no es Buenos Aires, un espacio legendario donde se despliega una trama de aventuras sobre el mito del coraje. Esta ópera prima de Hugo Santiago (con guión de Jorge Luis Borges y Adolfo Bioy Casares) es una máquina narrativa perfecta compuesta por partes iguales de criollismo y de fantástico: allí, un grupo de hombres "que no son héroes" se hacen matar para defender una ciudad asediada por poderosos invasores. Una tragedia moderna: melancólica y utópica a la vez.

Santiago realizó Invasión cuando tenía menos de 30 años. En ese momento, ya sabía todo lo que hay que saber. Esa obra inaugural, presenta con asombrosa madurez un proyecto estético perfectamente definido (en sus esquemas estilísticos, en sus vectores narrativos, en sus estructuras poéticas) que los films siguientes se ocuparán 
de desplegar y profundizar. Pero no es menos sorprendente que aún hoy la película conserve toda su potencia. Si se ha convertido en un discurso ubicuo sobre lo real, es precisamente porque profundiza su carácter de objeto autónomo. A mayor distancia, mayor poder de reflejo. Santiago responde con sencillez a la pregunta por el vínculo entre arte y realidad: es en su momento de mayor pureza, en su punto de mayor despojamiento cuando los films pueden hablar sobre el mundo. Colocándose afuera de la Historia (afuera del tiempo), Invasión queda disponible para albergar cualquier presente.

Y así como la batalla por Aquilea había anticipado la violencia política de los años 70 , quince años más tarde Las veredas de Saturno trae a escena el fantasma de un golpe militar justo cuando empezaban a gestarse los alzamientos carapintada. Ahora no se trata de una ciudad sitiada sino de un exilio: un músico que ha escapado a París luego de la invasión sueña con volver a Aquilea porque las manos se le endurecen y ya no puede tocar el bandoneón. Rodolfo Mederos interpretó al bandoneonista y, además, se ocupó de la música del film. En su diario, anotó que Santiago contribuyó a imprimir un giro radical en su manera de componer. Le explicaba que el personaje hacía tango de vanguardia y, entonces, lo obligaba a escuchar a Ravel, a Debussy, a Bach, a Beethoven, a Bartók, a Stravinsky, a Schönberg: “Tiene un grupo de cámara, es fanático de Bartók y su conjunto suena raro y moderno, para nada tonal. ¿Me entendés?. 'Sí, sí, Hugo, te entiendo', digo yo (y cada vez entiendo menos, en verdad)".

Santiago era lo contrario de un populista, pero (o quizás justamente por eso) sabía acercarse a ciertas zonas de la cultura popular con una mirada desprejuiciada que enaltecía los objetos sobre los que se posaba. El tango, el fútbol, el western, el cine negro: había entendido que, una vez que las historias se despojan del costumbrismo, ingresan al reino incesante de los arquetipos. Igual que Borges, consideraba que las películas de gángsters podían pensarse como un avatar moderno de la épica. Y llevada al extremo, la épica termina inevitablemente en derrota. El destierro (el exiliado lo sabe bien) es un lugar del que no se vuelve. Des-tierro es ausencia de una tierra donde hacer pie o donde hacer descansar los propios huesos. El final de Las veredas de Saturno es tan trágico como el de Invasión. Pero es más sombrío aún, porque no hay mayor desconsuelo que morir en tierra extranjera.

Después de Las veredas de Saturno, Hugo decidió que no iba a hacer más películas porque no estaba dispuesto a aceptar las condiciones de una industria que se había vuelto monstruosa y obscena. Pasó varios años realizando exquisitos documentales ensayísticos para la televisión (sobre Xenaquis, sobre el Quatuor Mosaïques, sobre Blanchot, sobre Aperghis, sobre puestas teatrales de Antoine Vitez) que él llamaba "objetos audiovisuales". Pero el deseo del cine fue más fuerte y, luego de un tiempo, decidió volver a hacer largometrajes de ficción. En 2001, terminó El lobo de la costa Oeste y, después de eso, se puso a pensar en una película que vendría a completar la saga de Aquilea y que se llamaría Adiós. Borges y Bioy ya habían muerto; Saer ya había muerto. Hugo decidió que, esta vez, escribiría el guión solo.

Un día de 2007, me llamó para decir que había escrito una primera versión. En la portada del texto decía:

Invasión: el sitio la lucha la invasión la resistencia - los muertos

Las veredas de Saturno: el exilio - y los muertos

Adiós: ¿el regreso imposible?

El film cuenta la historia del célebre científico Pinkhas-Molinero que, luego de muchos años en el extranjero, regresa a Aquilea donde se enfrenta a un presente y un pasado que se mezclan de manera inquietante. Hugo me dijo: "Te incluí como uno de los 
personajes de la película. A vos y a Adriana". En efecto, en el guión aparece una joven pareja, amiga de Pinkhas-Molinero, que recibe al científico cuando llega a Aquilea: el hombre y la mujer son sus confidentes y sus guías para atravesar ese sitio que, después de tantos años de ausencia, resulta un laberinto indescifrable para el recién llegado. Entonces, Hugo agregó: "Vos tenés que hacer lo mismo conmigo y con mi guión. Quiero que lo leas y que conversemos. Que me acompañes para atravesar ese terreno incierto. Tenés la obligación moral de ayudarme con esto". No quería un co-guionista para la nueva película; lo que necesitaba era una especie de sparring. Alguien que se entreverase con él, que le ofreciera resistencia para poner a prueba la fortaleza del texto, que devolviera sus golpes afirmativos en forma de preguntas. Alguien que lo escuchara. Así que durante un año, todos los meses, mantuvimos largas entrevistas telefónicas: el escribía y me enviaba sus avances para que yo los leyera y pudiéramos comentarlos. No creo que nada de lo que dije haya tenido alguna utilidad para el guión; pero recuerdo esos meses como una experiencia de intenso aprendizaje.

La película no se hizo. Era muy cara. Y Hugo estaba decidido a no filmarla si no podía hacerla tal como él quería. En algún momento se le ocurrió hacer El cielo del Centauro: un film pequeño que sirviera como laboratorio para ensayar algunas ideas y como renovada carta de presentación para conseguir el dinero que le permitiera realizar Adiós. El cielo del Centauro abrió el Festival Internacional de Cine Independiente de Buenos Aires en 2015. Pero ni siquiera así aparecieron los productores interesados en Aquilea. Y ya no hubo más tiempo. Hugo se enfermó y pasó mucho tiempo internado, con fuertes dolores y con un pronóstico cada vez mas pesimista. Sin embargo, siempre se negó a sentir pena de sí mismo y, en cada llamada telefónica, hacía esfuerzos por mantenerse activo y curioso como siempre: "Contame algo. ¿Qué películas viste? ¿En qué andan los chicos? ¿Cómo está la situación política de la Argentina? ¿Qué estás leyendo?"

Estuve con él en París, por última vez, poco antes de su muerte. Sabía y, a la vez no quería saber, que ya no lo vería más. Cuando salimos del bar para despedirnos, se puso a hacer payasadas, parado en el medio de la calle mientras los autos tocaban bocina. Tuve miedo de que fueran a atropellarlo; pero mis hijos lo adoraron. Ese cineasta, que hacía películas complejas sobre Blanchot y sobre Xenaquis, sabía ser la persona más encantadora del mundo. Me hizo un espectador más inteligente y más sensible. Y también me hizo feliz, porque fue mi amigo. 
